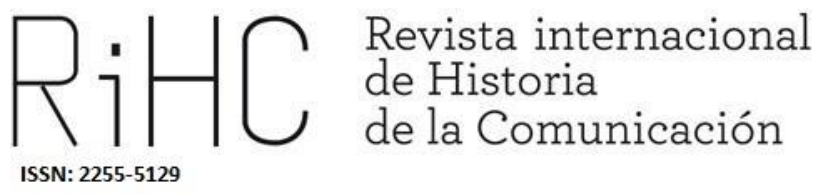

\title{
MUJERES GLADIADORAS. PRENSA REPUBLICANA FEMENINA Y MOVILIZACIÓN POLÍTICA EN LOS INICIOS DE LA CULTURA MEDIÁTICA EN ESPAÑA (1896-1922)
}

Gladiator women. Republican female press and political mobilisation in the beginning of media culture in Spain (1896-1919)

DOI: https://dx.doi.org/10.12795/RiHC.2020.i15.02

Recibido: $18-10-2020$

Aceptado: $25-11-2020$

Publicado: 30-12-2020

María Dolores Ramos Palomo

Universidad de Málaga, España

mdramos@uma.es

ORCID (iD 0000-0001-6189-1941

Víctor J. Ortega Muñoz

Universidad de Málaga, España

vjortega@uma.es

ORCID (i) 0000-0002-8472-4414

Como citar este artículo: RAMOS PALOMO, María Doloes y ORTEGA MUÑOZ, Víctor J. (2020): “Mujeres Gladiadoras. Prensa republicana femenina y movilización política en los inicios de la cultura mediática en España (1896-1922)", en Revista Internacional de Historia de la Comunicación, (15), pp. 16-41 
Resumen: El enorme potencial de la prensa republicana femenina española en el cruce de los siglos XIX-XX adquiere interés histórico debido a la renovación del mercado periodístico dirigido a las féminas, que trascendiendo el marco de las revistas de belleza, moda, hogar y economía doméstica acoge un periodismo político, doctrinario, militante y radical, dirigido y redactado por mujeres, aunque contara con colaboraciones masculinas. Esta prensa -El Progreso, La Conciencia Libre, El Gladiador, El Gladiador del Librepensamiento y Redención, entre otras publicaciones- confirió reconocimiento y autoridad intelectual a sus promotoras, al brindarles la posibilidad de difundir sus ideales, crear opinión, incidir en la esfera pública y articular una tradición política y cultural que en gran medida ha sido desestimada en la historia de la prensa.

Palabras clave: Prensa republicana, mujeres, cultura mediática, España, siglos XIX - XX.

Abstract: The enormous potential of the Spanish republican female press at the junction of the 19th-20th centuries acquires historical interest due to the renewal of the journalistic market aimed at women, which, transcending the framework of beauty, fashion, home and domestic economy magazines welcomes a political, doctrinaire, militant and radical journalism, directed and written by women, although it had male collaborations. This press - El Progreso, La Conciencia Libre, El Gladiador, El Gladiador del Librepensamiento and Redención, among other publications-conferred recognition and intellectual authority on its promoters, by giving them the possibility of spreading their ideals, create opinion, influencing the public sphere and articulating a political tradition and culture that has been largely neglected in the history of the press.

Keywords: Republican press, women, media culture, Spain, 19th - 20th centuries.

Cada letra del alfabeto hace más estragos que las instituciones de los reyes, que las excomuniones de los pontífices

María Marín

\section{Introducción}

El cruce de los siglos XIX-XX fue una etapa de contradicciones y transformaciones que propiciaron la irrupción de nuevos sujetos culturales, la crítica de las viejas ideologías, el auge de los cosmopolitismos y de la literatura social, haciendo confluir el ansia de renovación estética con una conciencia revolucionaria inclinada a subvertir de raíz el orden político y social. La necesidad de luchar por una vida más equitativa, racional y humana, planteada por la "Gente Nueva" en la revista Germinal contradice la creencia generalizada de que los modernismos fueron apolíticos (Ramos-Gascón, 1974: 126-127). Por otra parte, las transformaciones socioeconómicas experimentadas en el transcurso 
de la Segunda Revolución Industrial, las nuevas pautas de conducta y los modelos de feminidad y virilidad emergentes se vieron reflejados en narrativas, ensayos, poesías, artículos y editoriales, de acuerdo con el carácter diversificado de la modernidad y la jerarquización de las relaciones de poder producidas en numerosos ámbitos.

En cualquier caso, durante la crisis finisecular se crearon espacios de rebelión en los que algunas mujeres jugaron un papel decisivo, revitalizaron el lenguaje y las prácticas socioculturales (Zavala, 2001: 109). Entre estas prácticas cobraría singular importancia la fundación de una prensa propia, modesta, radical, combatida por las autoridades, donde tuvieron cabida ideas, valores y símbolos dirigidos a incidir en la esfera pública y la sociedad civil, fomentándose en ese proceso el reconocimiento de liderazgos femeninos desconocidos hasta aquellos momentos. Ligadas en buena medida al republicanismo, el anarquismo y el librepensamiento, varias propagandistas, activistas, escritoras y periodistas -todo a la vez- forjaron un linaje femenino rupturista: Belén Sárraga (1872-1950), fundadora de La Conciencia Libre, Ángeles López de Ayala (18561926) , impulsora de El Progreso, El Gladiador y El Gladiador del Librepensamiento, Ana Carvia Bernal (1865-1941) , directora de Redención, y su hermana Amalia Carvia (18611949), colaboradora en estos proyectos periodísticos. Mujeres consideradas "doblemente raras" por ligar su ideario político, su trabajo intelectual, su libertad de pensamiento y su rechazo del utilitarismo burgués -rasgos atribuidos por Rubén Darío a modernos, rebeldes, bohemios, radicales y vanguardistas en general en el libro Los raros (1905)- a su condición femenina, que las obligaba, de acuerdo con las normas socioculturales hegemónicas a permanecer en la esfera doméstica. En relación con este último aspecto hay que hablar de "modernidades sexualizadas" (Zavala, 2000). Así, mientras algunos colectivos femeninos trataban de reconstruir su subjetividad fuera del ámbito doméstico, creaban las redes de feminismo laicista de base republicana y se esforzaban por conseguir una ciudadanía igualitaria actuando en tres planos complementarios: periodístico, escolar y cívico-secularizador, los colectivos masculinos se esforzaban por potenciar, desde una perspectiva laicista, el papel socializador de las mujeres en los hogares republicanos; o bien por redefinir las identidades femeninas desde el punto de vista del erotismo y la práctica de la sexualidad fuera de la institución matrimonial, anticipando algunos rasgos del modelo de feminidad de los años veinte, el de la garçonne (Sanfeliu, 2006; Ramos, 2005, 2006a; Luengo, 2007a).

La labor periodística desarrollada por las mujeres republicanas proporcionó a los lectores en general, y a las lectoras en particular, la posibilidad de conocer discursos y prácticas de vida relacionados con los valores secularizadores y participativos de las formaciones políticas federales, blasquistas y lerrouxistas, la promoción de los derechos sociales, cívicos y políticos femeninos, y la adquisición de protagonismo en las redes sociales republicanas y librepensadoras. Estas experiencias permitirían desempeñar al menos a una generación de mujeres cometidos sociales y culturales más ambiciosos y culturales que los que les asignaba el modelo de "ángel del hogar". En este sentido, el 
concepto de cultura que utilizamos, más allá del propuesto por Burke (1991), no sólo tiene en cuenta las actitudes, los significados y valores compartidos y expresados en diferentes medios y actuaciones, sino la noción de "cultura vivida", es decir los aspectos referidos al trabajo, el ocio y la vida cotidiana, las representaciones y los referentes ideológicos presentes tanto en los espacios culturales dominantes como en los periféricos (Berger y Luckmann, 1993; Aguado y Ramos, 2002: 287-288). Respecto a la noción de "cultura mediática" en el cruce de los siglos XIX-XX, se aleja, obviamente, de las características de las tecnologías de la información y la comunicación (TIC) de la sociedad actual. La aplicamos a la capacidad de la prensa de opinión de construir discursos, experiencias, redes y sociabilidades, de moldear las conciencias, generar políticas regeneradoras y movilizaciones civiles en plena crisis de la "España sin honra" surgida tras la pérdida de la guerra colonial con Estados Unidos. A comienzos del siglo $X X$, particularmente después de la Gran Guerra, la modernización y las migraciones convirtieron a las ciudades en refugio de quienes reivindicaban el voto, buscaban un trabajo digno y pretendían el acceso a la educación (Giraldo, 2004: 96). Durante esos años el cine, el teatro y otros lugares de ocio se transformaron en espacios socializadores, de entretenimiento y consumo en la esfera pública hasta que la radio entró en la vida doméstica en la década de los treinta.

\section{1 "Somos las que fuimos y muchas más". Los periódicos republicanos femeninos en el marco de la prensa moderna}

El periodismo político se vio amenazado al finalizar el siglo XIX por uno nuevo de carácter noticiero, una prensa moderna que se constituye como empresa, que hace de la publicidad un instrumento de financiación y que asume el propósito de llegar a amplios sectores sociales. Esta nueva prensa intenta contestar la pregunta: ¿qué pasa por el mundo?; y al tratar de hacerlo y ante la imposibilidad real de conseguirlo en todas sus dimensiones, crea representaciones plurales de aquél integradas por las noticias más significativas, cuya elección, de acuerdo con los intereses de la empresa editora, otorga a determinados hechos la dignidad de ser publicados o no (Aguinaga, 2001: 241; Ortega Muñoz, 2019: 15-21).

En España se asistirá durante la Restauración, un periodo con menos libertades que el precedente, pero en el que el orden, el turno de partidos y las medidas económicas favorecerán la expansión capitalista, a la consolidación empresarial de la prensa y del nuevo modelo periodístico. Paulatinamente, los medios más reticentes van a ir aceptando parte de las innovaciones que observan en sus colegas con el fin último de 
expandirse, lo cual significó que diarios políticos consolidados (El Imparcial, El Globo, e incluso La Época o El Siglo Futuro) admitieran cierta flexibilidad en cuanto a la defensa política con el fin de atraer a los anunciantes y aumentar su tirada. Esta predisposición hacia el cambio, la búsqueda de nuevos lectores y la obtención de beneficios no transformará significativamente la relación existente entre el poder y la prensa, dado que en numerosas ocasiones van a ser coincidentes los intereses de los grupos editores y los poderes políticos (García Galindo, 2001: 91). Por otra parte, a principios del siglo XX, nos hallamos todavía ante un producto oneroso cuya transmisión se limita a los estratos sociales que pueden permitírselo, tanto económica como culturalmente, pero que en seguida circulará entre la pequeña burguesía y las clases populares. Una de las principales dificultades para la extensión de la prensa en las décadas precedentes había sido el elevado porcentaje de analfabetismo. En 1860 sólo sabía leer el 20\% de la población total; además, el proceso de alfabetización se realizó a un ritmo parsimonioso hasta 1877 (Botrel, 1993: 308), produciéndose el mayor descenso en los primeros años del siglo XX: un 66,55\% de analfabetismo en el conjunto del país en 1900 , un 59,35\% en 1910 y un $52,23 \%$ en 1920 (Samaniego, 1973).

La prensa diaria se desarrollará amparada por cierta estabilidad política y prosperidad económica, nacidas del régimen implantado por la monarquía restaurada. Con todo, la situación del "periodismo de masas", cimentado en el aumento de la tirada gracias a una reducción de precios y sostenida por la financiación publicitaria que abre la puerta a una mayor difusión y alcance, no alcanzó tiradas millonarias, aunque el estudio de sus cifras conlleva no pocas dificultades, debido a las deficiencias de la estadística de la época (Guereña, 1982: 81). Sin duda la publicidad fue un componente cada vez más importante en la estructura periodística, lo que despertó el deseo de obtener la mayor tirada posible, ampliar la cantidad de anunciantes y acrecentar la recaudación por anuncio (Seoane, 1977: 401). Efectivamente, la conversión empresarial de la prensa se vio reforzada con estas prácticas que sirvieron para que las cabeceras tuvieran mayores probabilidades de éxito. A ello se sumaron las entradas económicas obtenidas con la publicidad de folletos o libros diversos, que solían ser divulgados en los rotativos.

Pese a que las empresas periodísticas competían por atraer a las grandes figuras de la literatura y la política, el redactor fue una figura poco apreciada hasta que gradualmente llegó a convertirse en profesional de la comunicación. Serán las dos últimas décadas del ochocientos las que muestren al articulista en tanto que representante de una nueva profesión no exenta de dificultades y desarrollada en el marco de un periodismo basado en hechos, valores y emociones (Morales Lezcano, 1979). La presencia de redactoras y colaboradoras en las revistas y la prensa diaria era ya visible en el siglo XIX; no obstante, su trabajo se consideró irrelevante, marginal o, peor aún, sirvió en ciertos sectores para tildar a quienes lo realizaban con el mote de "marisabidillas". Nada más lejos de la realidad. Numerosas periodistas y escritoras llegadas a la arena pública en las primeras décadas del siglo XX no prestaron atención en sus respectivas publicaciones a las labores 
de ganchillo, sino que combatieron los discursos hegemónicos sobre la monarquía, la iglesia, el trabajo, la prostitución y el matrimonio, como demostró Carmen de Burgos en sus encuestas sobre el divorcio publicadas en El Diario Universal el año 1904. El radicalismo político, la rebeldía vital, la bohemia y la capacidad de civilizar de estas mujeres nos hablan de una modernidad conflictiva y de su apuesta por ampliar la ciudadanía. En el cruce de los siglos el periodismo femenino abarcaba un doble frente: por un lado, la edición de revistas magazine, con secciones dedicadas al hogar, la belleza, la salud, la familia y la economía doméstica, donde tenían cabida artículos informativos, noticias de actualidad, páginas literarias, incluso algunas entrevistas relacionadas con el movimiento de emancipación de las mujeres; y por otro, un periodismo político, doctrinario, militante, vinculado a las asociaciones femeninas republicanas y a otras entidades progresistas, dirigido y redactado por mujeres, aunque admitiera colaboraciones masculinas, que confirió reconocimiento y autoridad a sus promotoras, brindándoles la posibilidad de articular una tradición política en el marco de la cultura mediática que empezaba a consolidarse en España con la llegada del modernismo y sus numerosas manifestaciones editoriales, artísticas, literarias y urbanas. Esta prensa, cuyo estudio se ha desestimado hasta tiempos recientes, surgió en España en la coyuntura marcada por la guerra colonial en Cuba y Filipinas, los debates sobre la cuestión femenina, la cuestión obrera y la cuestión nacional, la dialéctica entre clericalismo/anticlericalismo y las controversias entre las familias políticas republicanas, y se convertiría en un instrumento mediador con capacidad para incidir en la transformación de las identidades, un vehículo transmisor de bienes culturales y un espacio de vindicación femenina que dotaría de contenidos ideológicos al público femenino que leía sus páginas.

La Conciencia Libre (1896-1907), El Gladiador (1906-1909), El Gladiador del Librepensamiento (1913-1919) y Redención (1915-1922), objeto de análisis en estas páginas, revelan la importancia de las tramas culturales republicanas, secularizadoras y feministas. Sus directoras, redactoras y colaboradoras fueron agentes de cambio social y utilizaron la prensa en tanto que elemento didáctico, socializador y movilizador, sin renunciar a otros recursos: libros y folletos publicados en fascículos, ensayos, reseñas, narrativas, poemas, traducciones y otros textos gracias a los cuales la circulación de las ideas fue más rápida e intensa (Berger y Luckmann, 1993: 46-52). Estos periódicos incorporaron a sus páginas debates políticos y culturales acordes con las claves identitarias de sus fundadoras: un nosotras que no pretendía borrar del escenario el vosotros referido a "todos los seres de ideas adelantadas". Por ello sus páginas incluían una Sección Masculina siguiendo las pautas del discurso de la complementariedad entre los sexos y el compromiso de lograr la igualdad de mujeres y hombres sin confrontaciones ni conflictos, ideas que reflejaban la cosmovisión ideológica plural, híbrida, transcultural y cosmopolita de librepensadores, masones y espiritistas en el marco de los modernismos (Lacalzada, 2007; Lasarte, 2001). El hecho de que las redactoras de El Gladiador del Librepensamiento y Redención introdujeran, a partir de 
1914-1915, artículos, editoriales y crónicas sobre los derechos civiles y sociales de las mujeres, sus movimientos de emancipación y el voto femenino confirma el giro del laicismo al sufragismo experimentado en el feminismo español durante la coyuntura de la Gran Guerra, la adopción de interesantes propuestas sobre la libertad de las mujeres y la creación de un tejido asociativo para lograr estos fines (Fagoaga, 1996: 171-198; Luengo, 2007b: 110-113; Sanfeliu, 2008: 59-78).

\section{Mujeres de La Conciencia Libre. Algo más que escritoras y periodistas: activistas}

Las mujeres de La Conciencia Libre -directora, redactoras, colaboradoras y lectorasrepresentaban los ideales de paz, progreso, cultura, emancipación, libertad, humanismo y universalismo propios de la cultura política republicana, y también un proyecto editorial inclinado a incidir favorablemente en la opinión pública sobre estas cuestiones. Así lo proclamaron en las páginas del semanario (1896-1906), realizando un ejercicio cotidiano de afirmación de sus identidades subjetivas y colectivas ${ }^{1}$. La idea de fundar $L a$ Conciencia Libre había surgido en Barcelona, en 1896, ligada a otro proyecto, la Asociación de Mujeres Librepensadoras, impulsado por Belén Sárraga Hernández, una joven republicana que a sus 23 años ya había destacado como oradora, propagandista, maestra laica y escritora en la "prensa de combate", asumiendo un liderazgo que la sociedad del momento consideraba impropio de su sexo (Ramos, 2006b). Tanto el periódico como la entidad femenina, cuyos estatutos fueron denunciados, tuvieron una vida efímera. Su promotora fue detenida porque sus ideas eran contrarias a la moral católica ${ }^{2}$.

El acoso policial llevó a Belén Sárraga a la ciudad de Valencia, donde se asentó hasta el año 1900. Allí materializó los proyectos suspendidos en Barcelona. Editó en 1896 La Conciencia Libre, con el respaldo del librepensamiento y la masonería, y creó la Asociación General Femenina en 1897. El periódico, dirigido por la joven escritora y editado con símbolos masónicos, incorporaba el lema "Libertad, Justicia, Fraternidad", tenía periodicidad semanal y contaba con un nutrido grupo de redactoras, la mayoría maestras laicas, propagandistas republicanas y escritoras que abrazaron la causa feminista y la defensa de la paz: las hermanas Amalia y Ana Carvia Bernal, Ángeles López

\footnotetext{
${ }^{1}$ La Conciencia Libre. Segunda Época. Año II, no 34, Málaga, 21 de julio de 1906.

${ }^{2}$ La Tramontana, no 709, 17 de abril de 1896.
} 
de Ayala, Soledad Areales y María Trulls ${ }^{3}$. La directora, iniciada en la logia valenciana "Severidad" en 1896, pronunció en su discurso de ingreso en la masonería unas palabras premonitorias: "Yo no he hecho nada, pero haré" (Ramos, 2006b: 697). Hizo mucho. Puso en marcha con sus compañeras el proyecto feminista laico, que contó con numerosas asociaciones de mujeres en todo el país, llevadas por la aspiración de crear "hermosas corrientes de solidaridad y apoyo mutuo", abrieron escuelas y bibliotecas, publicaron periódicos, libros y folletos, y extendieron los rituales secularizadores en la sociedad civil y lucharon contra la Monarquía.

La Conciencia Libre fue la tribuna de su ideario y de sus prácticas de vida (Sanfeliu, 2005: 102 y ss). En sus páginas hicieron campaña contra la guerra de Cuba y difundieron su participación en la Asamblea Internacional de Mujeres por el Desarme, organizada con motivo de la Conferencia de Paz de La Haya de 1899, entre otras actividades. La forma de proceder de las redactoras generó el rechazo de los sectores conservadores e integristas: "Las triunviras [en clara alusión a Ángeles López de Ayala y las hermanas Carvia Bernal] son de perlas... De Belén no hablemos. Armará tales belenes y tiberios que no se la podrá oír"4. Los comentarios jocosos y las descalificaciones verbales se hicieron habituales: "petroleras", "vesubianas", "agitadoras" e "incendiarias", entre otros insultos ${ }^{5}$. La redactora María Marín, incorporada a La Conciencia Libre en 1905, acumularía en su persona numerosos improperios: "herejota", "excomulgada", "rara", "arrebatada", "iconoclasta" 6 . El hecho de que estas mujeres rompieran las expectativas de género se agravaba por sus discursos y formas de vida, por aportar un ethos femenino, emancipador, filantrópico, mediador, secularizador y pacifista en el espacio público, que había sido diseñado como un espacio masculino, político, pero no moral (Béjar, 2001).

Pronto los juegos malintencionados de palabras dieron paso a persecuciones, detenciones y procesos. El semanario fue multado, secuestrado y clausurado en reiteradas ocasiones. Es revelador que entre abril y agosto de 1897 tuviera que hacer frente a dieciséis juicios, dos cierres en 1898 , el secuestro de los tres primeros números editados en Málaga en 1900 , en este caso "porque su directora era una mujer"7, y un nuevo cierre a finales de 1902, que llevó a Sárraga a publicar algunos ejemplares en Villa del Río (Córdoba), con el apoyo incondicional de las redactoras Amalia Carvia y Soledad Areales, la segunda expedientada y separada después de la enseñanza por sus ideas

\footnotetext{
${ }^{3}$ El Pueblo, 14 de julio de 1896.

${ }^{4}$ La Lectura Dominical, 21 junio de 1896.

${ }^{5}$ La Lectura Dominical, 4 marzo de 1900.

${ }^{6}$ La Conciencia Libre, Málaga, Segunda época, no 7, 18 de enero de 1906 y no 29, 16 de junio de 1906.

${ }^{7}$ Las Dominicales, 19 de abril de 1900.
} 
racionalistas $^{8}$, y el respaldo de la sociedad "Los Amigos del Progreso" ${ }^{9}$. El pacto de reconocimiento mutuo sellado el 9 de abril de 1901 entre Belén Sárraga y su "hermana en creencias" Soledad Areales, a imagen y semejanza del firmado por otras redactoras como Amalia Domingo Soler y Rosario de Acuña, o el suscrito entre Ángeles López de Ayala y Amalia Domingo Soler (Ramos, 2006a: 64-71), buscaba no sólo extender "la comunidad de ideas y los vínculos de la más íntima y fraternal amistad" entre ellas, sino consolidar sus lazos con el republicanismo radical y los grupos sociales avanzados en el campo socialista revolucionario y extender estas ideas en la prensa. La Conciencia Libre fue un elemento clave, a juicio de las redactoras: "Hemos contribuido a ensanchar las miras de muchos republicanos, enseñándoles a aceptar la República como un medio, no como un fin"10. Sin duda los pactos comprometieron a las juramentadas a jugar un activo papel cívico, social, secularizador y emancipador en la prensa, los centros culturales, los casinos políticos, incluso en la vida cotidiana, contribuyendo a consolidar un poder femenino emergente y numerosas voces de autoridad en las asociaciones y redes de mujeres.

En el Consejo de Redacción de La Conciencia Libre no sólo figuraban en 1901 las "infatigables luchadoras" que hacían posible su salida a la luz sino una nómina de políticos, intelectuales y otros representantes del magma ideológico y cultural de fin de siglo ${ }^{11}$ : los gestores de la corriente socialista-reformista no marxista (Ernesto Bark y Francisco Maceín), escritores vinculados a los ambientes modernistas y bohemios (Joaquín Dicenta, Felipe Trigo, Isidoro Lapuya), el promotor del socialismo revisionista (Rafael Delorme) y los republicanos Nicolás Salmerón García, Alejandro Lerroux, Nicolás Estévanez, Odón de Buen y Vicente Blasco Ibáñez. Todos agrupados en torno a la revista Germinal, dirigida por Dicenta, La República Social, conducida por Maceín, y La Conciencia Libre, de Sárraga. Establecer un "Pacto Revolucionario" con los anarquistas de la Revista Blanca era también objetivo de estos grupos. Las redactoras de La Conciencia Libre se encargaron de difundirlo: "Estamos conformes con ese pensamiento porque desde que entramos en la lucha, hace cerca de nueve años, no hemos seguido con la pluma, con la palabra y sobre todo con nuestros actos una política que no sea esa"12.

La trayectoria de La Conciencia Libre abarca dos épocas: la primera, desde 1896 a 1903, transcurrió entre Valencia y Málaga, donde se estableció a partir de 1900. Conscientes sus promotoras de la necesidad de abrise camino en el mercado de bienes culturales y de incrementar el número de lectoras/es, el periódico incorporó en sus páginas noticias

\footnotetext{
${ }^{8}$ La Conciencia Libre, Segunda Época, no 12, Málaga, 17 de febrero de 1906 y no 17, 24 de marzo de 1906.

${ }^{9}$ Las Dominicales, 24 mayo de 1900.

${ }^{10}$ La Conciencia Libre, Málaga, 7 septiembre de 1901.

11 La Conciencia Libre, Málaga, 12 de octubre de 1901.

12 La Conciencia Libre, Málaga, 14 de septiembre de 1901.
} 
culturales, comentarios de libros y la publicación de un folletín. En esta ciudad pasó a ser tribuna de opinión de la Federación Obrera Malagueña, entidad que adquirió tintes radicales en el contexto de crisis generalizada y "revolución cultural" de finales de siglo. Sus integrantes - republicanos, librepensadores, anarquistas y feministas- trasladaron a la sociedad civil sus prácticas políticas (Ramos, 2006a). El semanario fue portavoz de la Sociedad Progresiva Femenina de Málaga y de la Liga Anticlerical. 1902 fue un año de luces y sombras para La Conciencia Libre. Se convirtió en órgano oficial de la Federación Internacional de Librepensamiento, pero tuvo que lidiar una fuerte batalla con la poderosa oligarquía malagueña, representada por Amalia Heredia Livermore (18301902), marquesa de Casa Loring, incluso con otras fuerzas progresistas por la fuerte competencia ideológica que representaba para ellas ${ }^{13}$. La salida a la luz del diario EI Popular (1903), portavoz de Unión Republicana, y la beligerancia de La Unión Social, periódico impulsado en 1900 por Rafael Salinas, fundador del PSOE malagueño, fueron dos considerables escollos ${ }^{14}$. Con estos frentes abiertos, La Conciencia Libre recibió la orden gubernativa de echar el cierre en 1903.

Resurgió en 1905. Con una portada modernista en la que sobresalía una figura femenina de larga cabellera portando un globo terráqueo en la mano, metáfora de la proyección internacional de su ideario y del propio periódico. Los lemas "iGuerra a la hipocresía y la ignorancia!” y "¡Paso a la Ciencia y la Verdad!" eran una declaración de intenciones de las editoras:

Estamos en pie. Somos lo que fuimos y más de las que fuimos. Contadnos, los viejos amigos... contadnos e investigad nuestros pensamientos reflejados en estas columnas, ni una sola de nosotras abandonó su puesto; ni uno solo de los principios sustentados dejó de vivir en nuestros corazones ${ }^{15}$.

Belén Sárraga estaba arropada por Amalia Pérez Congiú, Amalia Carvia, Ángeles López de Ayala, Consuelo Álvarez Pool (Violeta), Lady Prado, María del Mar Cañamaque, María Marín, Soledad Areales y la veterana Amalia Domingo Soler, "maestra" de todas ellas. Entre los colaboradores extranjeros sobresalían las feministas Ida Altman (Alemania) y Nelly Rousell (Francia), y el diputado belga León Furnemont. Esta vez, la defensa de los valores republicanos, el fortalecimiento de la sociedad civil, el pacifismo y el feminismo compartieron espacios con la Crónica Internacional (Japón, Francia, Rusia, Iberoamérica), la propaganda sobre la Confederación Latinoamericana de Mariano José Madueño, director del periódico Mundo Latino, y las páginas culturales (literatura y avances científicos). El Congreso Universal de Librepensadores celebrado en Buenos Aires (1906) tuvo un gran seguimiento. Belén Sárraga, que formaba parte de la

\footnotetext{
${ }^{13}$ La Conciencia Libre, Málaga, 14 de junio de 1902.

${ }^{14}$ El Motín, 29 marzo de 1902.

${ }^{15}$ La Conciencia Libre, Segunda Época, no 1, Málaga, 2 de diciembre de 1905.
} 
delegación española, alcanzó allí fama internacional y fue invitada a varias giras propagandísticas por Argentina y Uruguay. Regresó a España a principios de enero de $1907^{16}$. Mientras tanto, La Conciencia Libre se había trasladado a Barcelona, la ciudad donde surgió once años antes. Instaladas en la calle Santa Madrona del barrio de Gracia, las redactoras hicieron saber su voluntad de continuar su larga vida de propaganda y de incidir en la opinión pública ${ }^{17}$. Pero la experiencia fue efímera. Las luchas contra el "regionalismo" de Solidaridad Catalana, las persecuciones políticas y la oferta de dirigir el diario El Liberal en Montevideo llevaron a Sárraga aquel mismo año a Uruguay.

\section{Las redactoras de El Gladiador se lanzan a la arena política}

El Gladiador vio la luz el 26 de mayo de 1906, en el barrio barcelonés de Gracia, en unos momentos de intenso desarrollo de la prensa republicana y obrera (La Revista Blanca, 1898; Tierra y Libertad, 1903; la transformación de El Socialista en diario en 1913), pese a que la lectura seguía siendo un hecho relativamente limitado en España (Botrel, 1991: 48). Su irrupción coincidió con la salida a la luz de Solidaridad Catalana, conglomerado ideológico regionalista, plural y bien articulado que acabó con Unión Republicana. Su directora fue Ángeles López de Ayala (1858-1926), asistida por un equipo de redactoras procedentes de la Sociedad Progresiva Femenina de Barcelona, mujeres de probada trayectoria republicana y feminista, con una experiencia editorial previa, respaldadas por un puñado de hombres ubicados en lo que se ha denominado el "feminismo masculino" de la Barcelona modernista, republicana, anarquista y bohemia del periodo finisecular (Ramos, 2005), que aspiraban a forjar un modelo de mujer secularizada que entonara con voz firme la Marsellesa, pero sin alterar los papeles de género. Evidentemnte, la sociabilidad republicana dirigida a la familia no iba más allá del interés por las escuelas laicas y la necesidad de apartar a las mujeres de los confesionarios (Sanfeliu, 2005).

La redacción y administración de El Gladiador se ubicaron en el piso principal de la calle Colón, 12, sede de la logia mixta "Constancia" a la que pertenecían la directora, algunas redactoras de la publicación y varios socios protectores. Estas estancias lindaban con la escuela laica femenina "El Progreso", donde impartía clases Ángeles López de Ayala, que vivía en la misma finca (Arkinstall, 2014). En estos espacios, tan diferentes de los despachos de los directores de las grandes empresas periodísticas, confluían proyectos

${ }_{16}$ La Conciencia Libre, Segunda Época, no 41, Málaga, 20 de octubre de 1906, № 49, 3 de noviembre de 1900, no 51, 17 de noviembre de 1906 y no 56, 22 de diciembre de 1906.

17 La Conciencia Libre, Segunda Época, № 57, 2 de marzo de 1907. 
políticos, culturales y cívicos. La directora y las redactoras, convencidas de que su tarea exigía dedicación y tiempo, se dejaban allí la vida en largas jornadas de trabajo, arropadas por la vecindad, que se jactaba de contar con un grupo de intelectuales racionalistas al que pertenecían escritoras, propagandistas, oradoras y maestras, y una "aristocracia artesanal" que incluía a modistas, bordadoras y sastras. Las calles pavimentadas, los círculos republicanos y ateneos populares, las logias masónicas, las escuelas laicas, los centros espiritistas, naturistas y feministas conferían al barrio de Gracia, fuente de tradiciones revolucionarias, un clima propio que favorecía los mítines, los debates, las tertulias, la lectura individual y colectiva, las actividades culturales y la distribución de la prensa (Romero Maura, 1975: 131-140). Recordemos que la ciudad letrada y el espacio urbano constituían a comienzos del novecientos una red simbólica y material en la que surgían prácticas sociales, agencias culturales y nuevas concepciones de la vida cotidiana (Zavala, 2001: 254).

La experiencia periodística de Ángeles López de Ayala venía de atrás. En 1891 había creado con las integrantes de la Sociedad Autónoma de Mujeres una tribuna de expresión republicana, laica y feminista: El Progreso. Una iniciativa efímera que sirvió para fundamentar la trayectoria del feminismo laicista y otorgar un importante crédito a las mujeres racionalistas. El periódico volvió a ver la luz en 1896 con la "sana intención" de luchar por la República, secularizar las costumbres y potenciar la acción social de las mujeres, erigiéndose en portavoz del republicanismo radical barcelonés. Una vez más la publicación sufrió registros, multas, suspensiones y procesos judiciales antes de cerrar sus puertas. Pero resurgió con fuerza el 1 de enero de 1900:

Hoy El Progreso se modifica en el sentido de ser órgano de la Sociedad Progresiva Femenina de Barcelona, de todas las Sociedades femeninas de la Península y de las mujeres obreras, a las que defenderá de las injusticias, abusos y atropellos de que sean objeto por parte de los patronos o los empleados de las fábricas donde trabajen (...) También habrá una sección especial, en la que se editarán aquellos trabajos que el sexo masculino nos envíe, siempre que estén dentro de nuestro hermoso credo de libertad y de justicia ${ }^{18}$.

El Progreso, como La Conciencia Libre y El Gladiador, pertenecía a la cuerda anticlerical de El Diluvio, El Motín, La Tramontana, La Campana de Gracia y L'Esquella de la Torratxa. Aunque estos periódicos eran la expresión de una pujante cultura popular, su trayectoria estuvo plagada de dificultades políticas y económicas. El Motín y La Tramontana afrontaron numerosas denuncias y el encarcelamiento de sus directores, José Nakens y José Llunas Pujals. Otro tanto le sucedió a La Conciencia Libre, cuya directora, Belén Sárraga, fue detenida varias veces en Valencia y Málaga. El Gladiador sufrió parecidas dificultades, pero se convertiría en un punto de referencia de las

${ }^{18}$ Las Dominicales del Librepensamiento, 17 de diciembre de 1899. El subrayado es de Ángeles López de Ayala. 
personas afines al campo del feminismo laicista y el republicanismo librepensador, gracias a la tenacidad de sus editoras, llegando a ser un puntal de lucha, resistencia y conexión con los grupos afines.

A la espera de que vea la luz la biografía elaborada por María Victoria Clemente Palacios sobre Ángeles López Ayala, en origen su Tesis Doctoral (2015), los perfiles de vida trazados sobre ella coinciden en señalar los rasgos de una mujer moderna, valerosa, fuerte e independiente, que supo resistir las adversidades y planteó numerosas luchas en diversos frentes (Ramos y Moyano, 2019). De ideales jacobinos, fue durante tres décadas cabeza rectora del feminismo laicista en España. Sus primeros contactos con las ideas progresistas se gestaron en Madrid, donde ingresó en la masonería. En 1889, tras asentarse en Barcelona, se afilió a la logia "Constancia" y creó, con la anarquista Teresa Claramunt y la espiritista Amalia Domingo Soler, la Sociedad Autónoma de Mujeres (1889-1892), una escuela de ciudadanas refundada después con el nombre de Sociedad Progresiva Femenina (1898-1926). Colaboró con Ferrer Guardia en el proyecto de la Escuela Moderna y redactó algunos libros (Primitivo, Abismos, Sol, Trinidad, Luz, Paz) utilizados en los centros escolares de dicha institución. Articulista y polemista, escribió piezas teatrales, cuentos, relatos históricos, poesías sociales y novelas didácticas. Dos veces se casó -en ambas ocasiones con masones- y dos veces enviudó. Acudió a varios congresos nacionales e internacionales de librepensadores, entre ellos el celebrado en Roma el año 1904, en compañía de Domingo Lozano, Odón de Buen, Emilio Ferrero y Belén Sárraga, y participó en numerosos mítines y actos propagandísticos, formando parte, en representación de la Sociedad Progresiva Femenina, de la Comisión Nacional creada para revisar el proceso de Montjuic. Mujer Infatigable, solía reaparecer dispuesta a dar la batalla tras sus estancias en la cárcel, como reconocían sus compañeros de filas: "Mientras otros dormían ella velaba..." 19. Adquirió autoridad, reconocimiento y legitimidad como directora de prensa, uniendo en su persona las facetas de maestra, periodista y presidenta de asociaciones femeninas (Bussy Genevois, 2005: 197 y ss.). Su capacidad de liderazgo se puso de relieve en la movilización anticlerical femenina celebrada en Barcelona en 1910, en la que participaron unas veinte mil mujeres de diferentes credos políticos (Ramos, 2005: 53-55). López de Ayala señaló los caminos que llevarían a la conquista del sufragio femenino. Sus luchas, dirigidas a combatir "los vicios sociales, políticos, religiosos", y a modificar las costumbres de su tiempo ${ }^{20}$, la hicieron muy popular en los sectores afines a sus proyectos, cosechando, en cambio, sentimientos de ira y rechazo en las filas conservadoras y clericales.

No estuvo sola en la tarea de forjar un periodismo que rompiera los esquemas de subordinación femenina desde la perspectiva republicana, anticlerical y sufragista. Como apunta Helena Béjar, la prensa reúne a quienes "necesitan encontrar un medio

\footnotetext{
${ }^{19}$ Las Dominicales del Librepensamiento, 30 de julio de 1899.

${ }^{20}$ El Gladiador, no 2, 8 de junio de 1906.
} 
de hablarse... sin verse y de marchar de acuerdo sin estar reunidos" (2000: 132). En la tarea de vincular a mujeres y hombres de ciudades, barrios y países, López de Ayala estuvo acompañada por las redactoras de "Los Gladiadores": la obrera Francisca Benaigues, natural de Valls (Tarragona) y vecina de Gracia, secretaria de la Sociedad Progresiva Femenina, una de las primeras mujeres que hizo público un testamento de rechazo de la fe católica, contraria a "la libertad de pensamiento, la conciencia laica universal, el civismo y los derechos naturales de la humanidad" 21; Dolores Zea, maestra laica y masona adscrita a la logia "Constancia", firme defensora de la paz, el feminismo y la fraternidad entre los pueblos; la espiritista María Vila; la lerrouxista Adelaida Molero, nacida en una familia republicana de clase media, afiliada a la Sociedad Progresiva Femenina (Ullman, 1972: 160); Francesca Diumenjó y Francisca Valdivia, tesorera y vocal respectivamente de la Progresiva; la anciana espiritista Amalia Domingo Soler, fundadora del periódico La Luz del Porvenir y el Centro La Buena Nueva, "mujer de palabra serena y tranquila, llena de afanes celestiales", uno de los puntales del feminismo laicista hasta su fallecimiento en 1909; la escritora Rosario de Acuña, otra pionera, promotora del primer pacto de solidaridad suscrito entre las mujeres librepensadoras (1887), feminista, pacifista y ecologista avant la lettre (Ramos, 2006a: 63; Hernández Sandoica, 2015) y la federal María Marín, redactora de La Conciencia Libre, colaboradora habitual en la prensa republicana, mujer de "espíritu independiente", maestra en el Nuevo Colegio Laico para niñas que funcionaba en Barcelona en 1917 y agitadora en los disturbios del pan que convulsionaron la capital catalana en $1918^{22}$. Unidas crearon varios cinturones de lectura de El Gladiador en Barcelona, utilizando sus redes sociales, y fomentaron su distribución en España, Portugal e Iberoamérica mediante sus contactos internacionales. Igual que sus compañeras de La Conciencia Libre, publicaron en el periódico folletines y novelas seriadas, como "El Abismo" y "Primitivo", escritas por Ángeles López de Ayala (Arkinstall, 2014).

Esta hermandad femenina aspiraba a emancipar a las mujeres en el marco del proceso de secularización emprendido a finales del XIX. Pero sus integrantes tuvieron que afrontar un clima general de incomprensiones, un auténtico "calvario", por parte de quienes pensaban que una librepensadora no podía ser "ni buena madre, ni buena hija, ni buena prostituta..." ${ }^{23}$. Las gladiadoras empeñadas en la tarea de arrancar a las mujeres del "poder del cura y alejarlas del convento" 24 sabían de lo que hablaban. Desarrollaron su activismo en un ambiente de fuerte movilización religiosa en el que

\footnotetext{
${ }^{21}$ El Gladiador, № 21, 26 de septiembre de 1907.

${ }^{22}$ Colaboradora de La Unión de Jerez, Heraldo de Cádiz, La Conciencia Libre, El Pueblo, El Federal y El Gladiador del Librepensamiento, entre otros periódicos.

${ }^{23}$ El Gladiador del Librepensamiento, no 99, 17 de febrero de 1917.

${ }^{24}$ El Gladiador, no 15, 16 de junio de 1906.
} 
proliferaban las manifestaciones de culto, las conferencias, asambleas y la organización de Ligas Católicas (Gutiérrez Lloret, 2008: 251 y ss.).

Feminidad y política habían dejado de ser términos excluyentes. En esa transformación tuvieron mucho que ver los discursos, los lenguajes críticos y la prensa que estamos analizando:

Venimos a reñir sangriento combate con las terribles fieras de todos los absurdos y de todas las preocupaciones con el mismo vigor y arrojo con que los gladiadores romanos pelean... Así nosotras, desnudas de toda protección y valimiento, nos precipitamos al circo de esta moderna Roma para exterminar a las fieras de la reacción o sucumbir entre sus garras formidables. Hasta la muerte lucharemos por la augusta trilogía: Libertad, Igualdad y Fraternidad, base fundamental de la redención humana ${ }^{25}$.

La forja de una identidad colectiva secularizada se puso a prueba en la contienda librada contra los republicanos que en 1907 se "desviaron del camino" y entraron a formar parte de Solidaridad Catalana, agrupación política que representaba para Ángeles López de Ayala un doble peligro: dividir a las fuerzas republicanas y divorciar a Cataluña del resto de España:

Sí: las librepensadoras, las republicanas sin apellidos, están obligadas a combatir sin descanso este orden de cosas tan inadmisible por lo perjudicial, animar voluntades haciendo comprender a los desunidos que sus diferencias hacen el juego a la reacción (...) Valor cívico, fortaleza y bravura, correligionarios, para cortar el mal por su raíz. ¡Arranquemos la cizaña, y renazca la unión, para que por su medio implantemos la república! ${ }^{26}$.

Las editoras de El Gladiador saludaron a la entidad catalanista con reservas: “iBienvenida sea... si no resta entusiasmo a los ideales redentores! ${ }^{27}$. Transcurridos unos meses, Ángeles López de Ayala contestaba a la pregunta: “¿Que es El Gladiador? ¿Lerrouxista o Solidario?": "Ni lo uno ni lo otro, porque afiliarse a una de estas dos facciones implica un personalismo contrario a la IDEA. Somos republicanas de la República.... Sin banderías" ${ }^{28}$. No obstante, Francisca Benaigues y Fernanda Valdivia declararon la guerra al separatismo, argumentando que "lo menor debe entrañar la absorción de lo mayor; y mayor que el bien de una región cualquiera es el bien de la

\footnotetext{
${ }^{25}$ El Gladiador, № 1, 26 de mayo de 1906.

${ }^{26}$ La Conciencia Libre. Segunda Época. Año II, no 65, Barcelona, 4 de mayo de 1907, p. 710.

${ }^{27}$ La Conciencia Libre, Segunda Época. Año II, no 65, Málaga, no 1, 26 de mayo de 1906.

${ }^{28}$ El Gladiador, no 4, 28 de agosto de 1906.
} 
Patria, y mayor que el bien de la Patria es el bien universal" ${ }^{29}$. Este confería, según la tradición ilustrada, derechos plenos a la humanidad.

La fractura estaba servida. Los republicanos "solidarios", respaldados por La Publicidad, El Diluvio, La Campana de Gracia, El Amigo del Pueblo y otros medios, veían las cosas de otro modo. Estaban convencidos de que la plataforma que habían creado serviría de contención a la monarquía y el militarismo, y crearía las bases para reformar la administración local y provincial. Pero ambos bandos, pese a sus diferencias, constituían un mundo virilizado en el que las gladiadoras, carentes de derechos, como todas las españolas, apoyaron finalmente a Lerroux. Acostumbradas a correr riesgos, afirmaron: "iLas grandes luchas son para las grandes almas!" 30 . Defensoras de la República Revolucionaria y Social y del concepto de Patria Universal, adoptaron el gorro frigio y cantaron "La Marsellesa" frente a quienes entonaban "Els Segadors". Pronto descubrieron que el feminismo no iba a ser medido con el mismo rasero que el anticlericalismo en las filas de Lerroux, quien se jactaba de haber conquistado a los obreros de Cataluña y a sus mujeres e hijos, aunque carecía de un proyecto político para las mujeres (Ullman, 1972: 161). Aun así, El Gladiador reivindicó reiteradamente los derechos sociales femeninos antes de que su voz fuera acallada en medio de la rebelión obrera y anticlerical surgida en la Barcelona de 1909.

\section{El Gladiador del Librepensamiento y Redención vindican el sufragio femenino}

El Gladiador resurgió en 1913 con un cambio en su cabecera, un formato de mayores dimensiones y una figura alegórica impresa en portada: la de un gladiador triunfante frente a la adversidad. De nuevo Ángeles López de Ayala, tras el rotundo éxito de la manifestación anticlerical femenina celebrada en 1910 (Ramos, 2005), asumió la dirección del periódico estableciendo la redacción en su domicilio: la calle Ferrer de Blanes, en el barrio de Gracia. El Gladiador del Librepensamiento tenía periodicidad quincenal, contaba con las redes de distribución establecidas en su primera época y podía adquirirse en los quioscos al precio de cinco céntimos, la mitad de lo que costaba El Gladiador, debido a la inclusión de una nutrida sección de anuncios en su última página, una importante novedad, y al incremento del número de personas "benefactoras" que enviaban periódicamente cantidades fijas para mantenerlo31. Por

\footnotetext{
${ }^{29}$ El Gladiador, № 1, 26 de mayo de 1906; № 13, 27 de abril de 1907, y no 16, 29 de junio de 1907.

${ }^{30}$ El Gladiador, 12 de octubre de 1907.

${ }^{31}$ El Gladiador del Librepensamiento no 33, 16 de mayo de 1914; n 93, noviembre de 1916; no 107, julio de 1917 y no 137, febrero de 1919.
} 
otra parte, las páginas se diversificaron con secciones sobre Movimiento por la Paz, Feminismo, Ciencia -a cargo de María Marín-, Deportes y Noticias, innovaciones que reflejaban los cambios producidos en la vida cotidiana y los modelos de género, así como algunas propuestas editoriales propias de la cultura mediática ${ }^{32}$.

El proyecto laicista defendido por El Progreso, La Conciencia Libre y El Gladiador, la prensa hermana, iba a ser reconducido hacia el sufragismo. Los vínculos con diferentes culturas políticas, la experiencia del asociacionismo, el aprendizaje del liderazgo y la irrupción de "voces de autoridad" reforzaron el acceso de las mujeres a la educación y el trabajo asalariado, el ejercicio de sus competencias intelectuales y profesionales, llevándolas a tomar conciencia de su individualidad y a materializar el ejercicio de la libertad. Para las "gladiadoras" la soledad era infinitamente mejor que "una compañía llena de inconvenientes ${ }^{33}$. Lo comentaba Antonia Miralles:

Yo quiero un mañana de mujeres que sepan que no hay nada imposible para su inteligencia femenina por estar convencidas de que no son inferiores en ningún aspecto a los hombres. Que dediquen su actividad a un determinado saber o a una determinada ocupación. Quiero mujeres que no sean estorbos en los apuros económicos, que sepan ganarse la vida, luchar contra la misma, teniendo un temperamento fuerte y un corazón noble ${ }^{34}$.

La clave de la emancipación femenina residía en la independencia material, que se consideraba la base del feminismo político y el sufragio. La conquista de espacios culturales, el ejercicio de nuevos oficios (cajeras, mecanógrafas, reporteras, telefonistas, telegrafistas, bibliotecarias, secretarias), el estudio de carreras universitarias, el desempeño de las cátedras y la aceptación por los varones de estos cambios identitarios, equivalían a reconstruir los papeles de género ${ }^{35}$. El feminismo pasó a ser un proyecto político y un movimiento social con capacidad para transformar las ideas, las mentalidades, los sentimientos y el imaginario colectivo ${ }^{36}$. La transición se hizo de forma gradual: los artículos de Amalia Carvia y María Marín en El Pueblo (1909-1910), la participación de Belén Sárraga en el Primer Congreso Internacional Feminista de Buenos Aires (1910), la petición del sufragio femenino que hizo Ángeles López de Ayala en el Congreso Nacional de la Libertad (1912), y la fundación de Redención por Ana Carvia Bernal (1915) constituyeron hitos significativos. Poco antes de que El Gladiador del Librepensamiento desapareciera en noviembre de 1919, López de Ayala y las redactoras, esgrimiendo las consignas "ilgualdad ante la ley"! y “iDonde hay deberes, deben existir

\footnotetext{
32 El Gladiador del Librepensamiento, n 46, 5 de diciembre de 1914.

${ }^{33}$ El Gladiador del Librepensamiento, no 99, febrero de 1917.

${ }^{34}$ El Gladiador del Librepensamiento, no 92, noviembre de 1916.

${ }^{35}$ El Gladiador del Librepensamiento, no 93, noviembre de 1916 y no 94, diciembre de 1916.

${ }^{36}$ El Gladiador del Librepensamiento, no 109, noviembre de 1917.
} 
derechos!", avanzaron su rechazo del sufragio censitario por considerar que éste se convertiría en patrimonio de un pequeño, aunque selecto, grupo de mujeres intelectuales:

No, amigas mías, no es ese el modo de hundir el fuerte recinto de las injusticias sociales; la mujer tiene derecho a ser educada intelectual, moral y físicamente en las mismas condiciones en que se educa a los hombres, como tiene derecho a que políticamente se la eduque. Y esta última cuestión se adquiere con la práctica que de los actos que de la cuestión política se infieren. ${ }^{37}$

La revista Redención vio la luz en Valencia el 1 de septiembre de 1915 con el subtítulo "Revista mensual feminista" ${ }^{38}$. Impulsada por Ana C[arvia] Bernal, que firmaba así sus escritos para resaltar su filiación materna, logró publicar, a pesar de las dificultades económicas, 79 números, hasta junio de 1922 (Almisas Albéndiz, 2019: 196). El título, claro símbolo de sus intenciones, iba dirigido a las mujeres que pensaban y sentían la necesidad de trabajar por la emancipación femenina en todos los campos. Su directora no era una desconocida, aunque había mantenido un bajo perfil mediático desde que puso en pie, con Belén Sárraga y otras compañeras, la Asociación General Femenina, de la que fue secretaria, y otros proyectos en la ciudad de Valencia. Compaginó toda su vida la docencia en las escuelas laicas, la lucha pacifista, las campañas para erradicar la prostitución y el alcoholismo y la reivindicación de los derechos de las mujeres, en consonancia con la agenda del feminismo internacional. Ana C. Bernal gestó la revista Redención rodeada de un grupo de redactoras que contaban con una reconocida experiencia al frente de publicaciones hermanas -La Conciencia Libre, El Gladiador y EI Gladiador del Librepensamiento- decididas a lanzar la revista con "el aliento de nuestras almas" y el de quienes "simpaticen con el ideal redentor y feminista": Ángeles Guiñón, Josefa Carneiro, Consuelo Álvarez Pool (Violeta) y a partir de diciembre de 1915 Amalia Carvia, hermana de la directora (Luengo, 2003: 103-113). Efectivamente, donativos, suscripciones y adhesiones, como las de las "gladiadoras" María Marín y Ángeles López de Ayala, no tardaron en llegar mientras la publicación se difundía en Valencia, Barcelona, Madrid, Huelva y otras ciudades gracias a las redes construidas por el feminismo laicista en años anteriores ${ }^{39}$.

La portada era muy sencilla. Tras el número y la fecha en minúsculas, resaltaba el título de la revista en grandes dimensiones, subrayando así el interés del mensaje, y el subtítulo. Dos grandes recuadros paralelos con citas de Fenelón y Rousseau sobre la importancia de la educación femenina seguidos, debajo, por el lugar de edición completaban el conjunto. El segundo número incorporó algunas novedades: el título

\footnotetext{
37 El Gladiador del Librepensamiento, № 147, 18 de octubre de 1919.

${ }^{38}$ Redención (Valencia), no 1, septiembre de 1915.

${ }^{39}$ Redención, no 2, octubre de 1915.
} 
enmarcado en un rectángulo, dos pilastras recorridas por pequeñas hojas y los dos recuadros con las citas que ya conocemos, a los que se había añadido una tercera cita de Concepción Arenal, figura elegida por las feministas valencianas que protagonizaron la transición del laicismo al sufragismo. Pronto la revista se distribuyó en Portugal, Italia, México Cuba y otros países latinoamericanos, promoviendo intercambios de publicaciones y sobre todo vínculos, que se consolidaron en seguida, con algunas feministas como la mexicana Hermila Galindo y la uruguaya Luisa Paulini. Redención incluyó artículos sobre "el séptimo arte" con la intención de hacer reflexionar a sus lectoras sobre las historias, los personajes y los arquetipos mostrados en las películas y la capacidad del cine para incidir en la transformación de las identidades. Y pese a sus escasos recursos económicos, reprodujo algunas fotografías en su portada a partir de 1920, sobresaliendo entre ellas la dedicada a la Cruzada de Mujeres Españolas de Carmen de Burgos en el momento de manifestarse en las calles madrileñas para reivindicar el sufragio, publicada en julio de 1921.

Entre los temas tratados en la revista cabe destacar la respuesta pacifista al conflicto bélico internacional, la reforma del Código Civil, en especial el derecho de familia ${ }^{40}$, el antialcoholismo, siguiendo las directrices del Consejo Nacional de Mujeres Francesas ${ }^{41}$, la dignificación de la vida en las cárceles, la denuncia de la prostitución, que se cebaba con las mujeres más jóvenes y pobres, y la defensa de la educación femenina ${ }^{42}$. Al hacer balance del primer año de vida, las redactoras encontraron cierta tibieza en las lectoras: "Como si la cosa no interesara grandemente. [Igual que] el sonámbulo que se resiste a sacudir el extraño sueño que le enerva y destruye su personalidad consciente" 43 . A pesar de esta percepción negativa, pronto llegaron tiempos mejores ${ }^{44}$. Redención logró abanderar la fundación en enero de 1917 de la Sociedad Concepción Arenal, surgida para laborar por la cultura y el civismo de la mujer y conseguir que las feministas españolas "fueran dignas hermanas de las nobles feministas europeas" 45 . Antes de que finalizara el año, Ana C. Bernal difundió en la revista la fundación de la Liga de Mujeres Españolas, entidad respaldada por Ángeles López de Ayala, la Sociedad Progresiva Femenina y El Gladiador del Librepensamiento en Barcelona ${ }^{46}$. En abril de 1918 se dio a conocer el proyecto y se envió a la prensa el manifiesto "A las mujeres españolas",

\footnotetext{
${ }^{40}$ Redención, no 6, febrero de 1916.

${ }^{41}$ Redención, no 9, mayo de 1916.

42 Redención, no 12, septiembre de 1916.

${ }^{43}$ Redención, no 13, octubre 1916.

${ }^{44}$ Redención, no 17, enero de 1917.

${ }^{45}$ Redención, no 25, septiembre de 1917.

${ }^{46}$ Redención, no 30, febrero 1918.
} 
publicado en Redención ${ }^{47}$. La Liga, organizada en Valencia, contaba en su Junta Directiva con Ana C. Bernal, presidenta; su hermana Amalia Carvia, secretaria, y Ángeles Guiñón, vocal, entre otras mujeres ligadas a la revista.

En 1919, a instancias del ministro conservador Burgos Mazo, el Consejo de Ministros aprobó un proyecto de ley sobre el sufragio femenino, restringido por la edad y por la imposibilidad de que las mujeres fueran elegibles. La Liga exigió el voto sin limitaciones. Pero el gobierno cayó y las expectativas quedaron en el aire. Una nueva entidad, el Consejo Supremo Feminista de España, presidido por María Espinosa de los Monteros y al que pertenecieron Ángeles López de Ayala y Ana C. Bernal, adoptó esa reivindicación. Redención ${ }^{48}$ cubrió la información y publicó las fotos de la Junta Directiva. Aunque el ritmo de la historia iba en otra dirección. Pasados unos años, Clara Campoamor y otras feministas retomaron la reivindicación del sufragio en 1931, en unos momentos en los que el periodismo femenino comenzaba a ser una actividad profesional (Díaz Nosty, 2020).

\section{Conclusiones}

En este artículo se han explorado algunas de las implicaciones políticas, sociales y culturales que la historia del periodismo aporta al conocimiento de la sociedad española en el cruce de los siglos XIX-XX, a partir del papel desempeñado por las mujeres republicanas en la prensa, de la repercusión de sus iniciativas, de su incidencia en la opinión pública y de sus aportaciones al mercado de bienes culturales: inclusión de novelas seriadas, anuncios publicitarios, fotografías, informaciones sobre teatro, cine, deportes, música, libros y temas científicos, y creación de modestas colecciones editoriales ligadas a las cabeceras de sus periódicos.

Desde el enfoque de la historia cultural nos hemos aproximado a unas fuentes hemerográficas que, pese a estar alejadas de las grandes empresas periodísticas de la época, fundamentalmente los diarios de mayor tirada -El País, Heraldo de Madrid, La Vanguardia-, contribuyeron a construir un espacio democrático, moderno, social y literario, a la par que a difundir discursos, propuestas, lenguajes y narrativas procedentes de sectores feministas, progresistas, republicanos, bohemios, trasgresores, obreristas o pequeñoburgueses. De acuerdo con Rubén Darío (2005), que consideraba el periodismo como un campo de batalla, la prensa republicana femenina debió superar vicisitudes políticas (censura, retirada forzosa de ejemplares en los

\footnotetext{
${ }^{47}$ Redención, no 33, mayo de 1918. La Liga tenía como presidenta a Ana C. Bernal, a Amalia Carvia en la función de secretaria y Ángeles Guiñón como vocal.

${ }^{48}$ Redención (Valencia), no 50, diciembre de 1919.
} 
puestos de ventas) y económicas (multas, cierre temporal o indefinido de las cabeceras), con la finalidad de convertirse en una herramienta civilizadora, socializadora, comprometida con un ideario democrático e igualitario que interpelaba al Estado de la Restauración.

Los periódicos estudiados cuestionan el tradicional discurso sexuado que atribuye a los hombres la parte crítica e informativa de la prensa -editorial, noticias políticas en primera página, informaciones de actualidad, comentarios sobre los avatares socioeconómicos-, es decir la "parte alta del periódico", desertando de la "planta baja" conformada por las crónicas sobre el hogar, la moda y la familia, que se relacionan con un tiempo circular, reproductivo y doméstico. La publicación en 1897 de La Fronde, primer periódico francés dirigido, redactado, compuesto y distribuido por mujeres, constituye un ejemplo paralelo al representado por La Conciencia Libre, El Gladiador, EI Gladiador del Librepensamiento y Redención. El análisis de estas publicaciones revela interesantes perspectivas para investigar la historia de la prensa a partir de un enfoque de género, muestra el rol de las mujeres en la construcción de la opinión pública, asociado al "giro cultural" introducido por el modernismo, y la irrupción de nuevos ritmos temporales, urbanos, regidos por prácticas de vida y hábitos a los que no serán ajenos la lectura individual y colectiva, sometida a discusiones y debates en las tertulias de los cafés y las sesiones de controversia organizadas en los casinos populares y ateneos obreros de las ciudades.

Si hay elementos económicos de la prensa moderna difícilmente constatables en "nuestras" publicaciones, como los beneficios de las grandes empresas periodísticas, hay otros rasgos que los ligan con la cultura mediática en el cruce de los siglos, por ejemplo, las formas de sociabilidad entre intelectuales, el interés por incrementar el número de lectores/as y la necesidad de llegar cada ves más lejos, hacer ruido y crear opinión. Directoras, redactoras y colaboradoras -escritoras y activistas culturales a un tiempo-, pese a no estar reconocidas como profesionales del periodismo, mostraron en sus editoriales, artículos y noticias su pertenencia al llamado "pelotón intelectual de entre siglos", favoreciendo en la coyuntura de la Primera Guerra Mundial el proceso de creación de nuevas profesiones femeninas, incompleto, conflictivo y con serios altibajos en unos años en los que surgieron las primeras cronistas y corresponsales avant la letre (Sofía Tartilán, Carmen de Burgos, entre otras). Fueron "trabajadoras de prensa" capacitadas para seleccionar la información, escribir en cualquier sección del periódico que requiriera su presencia, crear opinión, traducir textos y participar en el diseño, la edición y los canales de distribución. Este proceso de disponibilidad total las llevó en el marco de la cultura mediática de entresiglos a adoptar estrategias de esparcimiento y de captación del público lector, incluyendo folletines dramáticos y novelas didácticosociales por entregas, como El Abismo y Primitivo, escritas por Ángeles López de Ayala y publicadas en El Gladiador, siguiendo el ejemplo de escritores como Zola y Sue. La construcción de dicha cultura en los últimos años del "largo siglo XIX"- como ha sido 
denominado por Tuñón de Lara y Hobsbawm, entre otros historiadores- no sólo implicaría el cambio de hábitos del público al que iba va dirigida y la apertura de nuevos mercados culturales, sino la irrupción de redactores (as), corresponsales y colaboradores (as), a veces extranjeros, que debían ajustar el proceso de escritura a los ritmos periódicos -diarios o semanales- de las publicaciones y a los tiempos modernos que surcaban la vida cotidiana.

Las Gladiadoras crearon canales de distribución y circulación para fomentar las suscripciones, alimentar las ventas callejeras y la presencia de sus publicaciones en los quioscos, construyendo "cinturones de lectura" próximos, de carácter local, nacionales e internacionales. Desaparecida La Conciencia Libre en 1907, el cambio de formato, la segmentación de los contenidos, las novedades gráficas y el incremento de la publicidad se apreciarán sobre todo en EL Gladiador del Librepensamiento. La coyuntura de la Primera Guerra Mundial puede considerarse el marco idóneo, dado el acelerado proceso de feminización del mercado laboral impuesto por las circunstancias bélicas, para construir la figura de la mujer periodista con unos criterios profesionales que en España no serán plenamente visibles hasta la Segunda República.

La Conciencia Libre, "Los Gladiadores", y en mayor medida Redención, el primer periódico sufragista español, no pueden considerarse un ejemplo de prensa de partido, pese a que sus redactoras estuvieran adscritas a las culturas políticas progresistas, sino que representan un espacio inclinado a la difusión y el debate de ideas democráticas, igualitarias, feministas, emancipadoras, secularizadas y secularizadoras; espacio dedicado, consecuentemente, a formar la opinión del público con estos planteamientos. En la prensa analizada hemos visto reflejadas identidades, ideas, relaciones sociales, prácticas políticas, voces de autoridad y circunstancias plurales. Sus editoras construyeron perfiles subjetivos y colectivos, moldearon conciencias y generaron movilizaciones políticas, difundiendo discursos y prácticas de vida con objetivos didácticos, movilizadores, socializadores y reivindicativos, desde el entendimiento, la cooperación y la pluralidad. Dieron cauce al feminismo laico primero y a la causa sufragista después, posibilitando así el avance de las españolas hacia la "cosa pública" en los años veinte y treinta del pasado siglo.

\section{Referencias bibliográficas}

AGUADO, A. y RAMOS, M.D. (2002): La modernización de España (1917-1939), Cultura y vida cotidiana. Madrid, Síntesis.

AGUINAGA, E. (2001): “Hacia una teoría del periodismo". Estudios sobre el mensaje periodístico, no 7, 2001, pp. 241-255. 
ALMISAS ALBÉNDIZ, M. (2019): ¡Paso a la mujer! Biografía de Amalia Carvia. El Puerto de Santa María (Cádiz), Suroeste.

ARENDT, H. (1988): Sobre la Revolución, Madrid, 1988.

ARKINSTALL, Ch. (2014): Spanish Female Writers and the Freethinking Press. 1879-1926. Toronto, University of Toronto Press.

BÉJAR, H. (2001): El corazón de la República. Avatares de la virtud pública, Barcelona, Paidós.

BERGER, P. y LUCKMANN, T. (1993): La construcción social de la realidad, Buenos Aires, Amorrortu.

BOTREL, J.F. (1993): Libros, prensa y lectura en la España del siglo XIX. Madrid, Fundación Germán Sánchez Ruipérez.

BOTREL, J.F. y DESVOIS, J.M. (1991): "Las condiciones de la construcción cultural", en Salaün, S. y Serrano, C. (eds.), 1900 en España, Madrid, Espasa-Universidad.

BURKE, P. (1991): Formas de hacer historia. Madrid, Alianza.

BUSSY GENEVOIS, D. (2005): "La función de directora en los periódicos femeninos o la "sublime misión»", en Desvois, J.M. (coord.), Prensa, impresos, lecturas en el mundo hispánico. Homenaje a Jean-François Botrel, Burdeos, Université Michel de Montaigne, pp. 193-208.

CHARTIER, R. (1994): El mundo como representación. Barcelona, Gedisa.

CLEMENTE PALACIOS, M.V. (2015): Ángeles López de Ayala (1858-1926): un icono del librepensamiento en la España de entresiglos. Tesis doctoral, Universidad Complutense de Madrid.

DARIO, R. (1905): Los raros, Barcelona, Maucci.

DÍAZ NOSTY, B. (2020): Voces de mujeres periodistas españolas del siglo XX nacidas antes del final de la Guerra Civil. Sevilla, Renacimiento.

FAGOAGA, C. (1996): "De la libertad a la igualdad: laicistas y sufragistas", en Segura, C. y Nielfa, G. (eds.), Entre la marginación y el desarrollo. Mujeres y hombres en la Historia. Homenaje a $M^{\underline{a}}$ Carmen García-Nieto, Madrid, Ediciones del Orto, pp. 171-198.

GARCÍA GALINDO, J.A. (2001): "Élites y prensa en Andalucía durante la Restauración", en AUBERT, P. y DESVOIS, J.M. (eds.): Les élites et la presse en Espagne et en Amérique latine des Lumières à la seconde guerre mondiale. Madrid, Casa de Velázquez, pp. 89-110. 
GIRALDO RAMÍREZ, M.E. (2004): "De la cultura de masas a la cultura mediática. Un análisis de los media desde la comunicación", Anagramas. Rumbos y sentidos de la Comunicación, vol. 3, no 5, 2004, pp. 91-114.

GUEREÑA, J.L. (1982): “Las estadísticas oficiales de la prensa (1867-1927)”, en Barrère, B. y otros: Metodología de la historia de la prensa española. Madrid, Siglo XXI.

GUTIÉRREZ LLORET, R.A. (2008): “iA las urnas, en defensa de la fe! La movilización política católica en la España de comienzos de siglo XX", Pasado y Memoria. Revista de Historia Contemporánea (Universidad de Alicante), no 7, 2008, p.p. 239262.

HERNÁNDEZ SANDOICA, E. (2016): “El poder ambidiestro del lenguaje: Género, injuria y sexualidad en "La Jarca de la Universidad" de Rosario de Acuña, 1911", en Hernández Sandoica, E. (ed.), Espacio público y espacio privado. Miradas desde el sexo y el género. Madrid, Abada Editores, pp. 95-169.

HUERTAS, E. (1996): “El Grupo Germinal y el librepensamiento español”, en Álvarez, P. (ed.), Librepensamiento y secularización en la España contemporánea, Madrid, Universidad Pontificia de Comillas, pp. 265-296.

LAERA, A. (2008): “Cronistas, novelistas: la prensa periódica como espacio de profesionalización en la Argentina (1880-1910), en Altamirano, C. y Myers, J. (coords.), Historia de los intelectuales en América Latina. Tomo I: La ciudad letrada, de la conquista al modernismo. Madrid, Katz Editores, pp. 495-522.

LASARTE, J. (2000): "Pueblo y mujer. Figuraciones dispares del intelectual moderno", en Escaja, T. (comp.), Delmira Agustini y el modernismo. Nuevas propuestas de género, Rosario, Beatriz Viterbo Editora, pp. 38-54.

LACALZADA, M.J. (2007): El cimiento mixto en masonería. El Derecho Humano en España (1893-1963), Madrid, Fundación Marie Deraismes.

LUENGO, J. (2007a): “Mujeres bohemias. Ocio, modernidad y resignificación identitaria” (Dossier), Arenal. Revista de Historia de las Mujeres, no 14 (2), 2007, pp. 213-30.

- (2007b): "Redención, una revista feminista en pro de la igualdad entre los sexos", en Taillefer de Haya, L. (coord.), Avanzando hacia la igualdad en las Humanidades, Málaga, Diputación de Málaga, pp. 103-113.

MARTÍNEZ MARTÍN, J.A. (2005): “La lectura en la España contemporánea: lectores, discursos y prácticas de lectura", Ayer, no 58, 2005, pp. 18-27.

MORALES LEZCANO, V. (1979): “"Revista España», semanario de la vida nacional (19151924)". Hispania, 1979, no 39 (141), 1979, pp. 201-220. 
ORTEGA MUÑOZ, V.J. (2019): iExtra, extra! Poder, información y control de la sociedad española en las noticias de sucesos, 1881-1923, Zaragoza, Pórtico.

RAMOS-GASCÓN, A. (1974): "La revista Germinal y los planteamientos estéticos de la Gente Nueva”, en VV.AA., La crisis de fin de siglo. Ideología y literatura. Estudios en memoria de Rafael Pérez de la Dehesa, Barcelona, Ariel, pp. 124-142.

RAMOS, M.D. (2006a): "La República de las librepensadoras (1890-1914): laicismo, anticlericalismo y emancipismo", en Ramos, M.D. (ed.), República y republicanas en España, Madrid, Marcial Pons, pp. 45-74.

- (2006b): "Belén de Sárraga. Una «obrera» del laicismo, el feminismo y el panamericanismo en el mundo ibérico", Baetica, no 28, 2006, pp. 689-708.

- (2005): "Hermanas en creencias, hermanas de lucha. Mujeres racionalistas, cultura republicana y sociedad civil en la Restauración", en Ramos, M.D. (coord.), "Laicismo, identidades, culturas políticas: Mujeres fragmentadas" (Dossier), Arenal. Revista de Historia de las Mujeres, 11:2, pp. 27-56.

RAMOS PALOMO, M.D. y MOYANO RAMOS, I. (2019): “Una republicana sin república: Ángeles López de Ayala (1856-1926). Liderazgo político, laicismo y compromiso feminista", en Ramos Palomo, M.D. y Ortega Muñoz, V.J. (coord.), Biografías, identidades y representaciones femeninas. Una cita con la historia, Zaragoza, Pórtico, pp. 185-210.

ROMERO MAURA, J. (1975): La Rosa de Fuego. Republicanos y anarquistas. La política de los obreros republicanos entre el Desastre Colonial y la Semana Trágica, Barcelona, Grijalbo.

SAMANIEGO, M.D. (1973): “El problema del analfabetismo en España (1900-1930)", Hispania, no 124, 1973, pp. 375-400.

SANFELIU, L. (2011): “Amalia y Ana Carvia Bernal, maestras laicas y educadoras cívicas, en Celada Parandones, P. (coord.), Arte y oficio de enseñar. Dos siglos de perspectiva histórica. Vol. II, Burgos-Valladolid, Sociedad Española de Historia de la Educación y Universidad de Valladolid, pp. 807-816.

- (2008): "Del laicismo al sufragismo: marcos conceptuales y estrategias de actuación del feminismo republicano entre los siglos XIX y XX", Pasado y Memoria. Revista de Historia Contemporánea, no 7, 2008, pp. 59-78.

- (2005): Republicanas. Identidades de género en el blasquismo (1895-1910), València, Universitat de València.

SEOANE, M.C. (1977): Oratoria y periodismo en la España del siglo XIX. Valencia, Castalia. 
ULLMAN, J.C. (1972): La Semana Trágica. Estudio sobre las causas socioeconómicas del anticlericalismo en España (1898-1912), Barcelona, Ariel.

ZAVALA, I.M. (2001): El rapto de América y el síntoma de la modernidad. Barcelona, Montesinos, 2001.

- (2000): "Modernidades sexualizadas: el corredor de las voces femeninas", en Escaja, T. (comp.), Delmira Agustini y el modernismo. Nuevas propuestas de género, Rosario, Beatriz Viterbo Editora, pp. 109-122. 